Revista Destaques Acadêmicos, Lajeado, v. 13, n. 2, 2021. ISSN 2176-3070

DOI: http://dx.doi.org/10.22410/issn.2176-3070.v13i2a2021.2595

http://www.univates.br/revistas

\title{
IMPLICAÇÕES DA PRÁTICA DO VOLEIBOL ESCOLAR NOS HÁBITOS ESPORTIVOS NA IDADE ADULTA
}

\author{
Gustavo Eugênio Koerbes ${ }^{1}$, Rodrigo Lara Rother ${ }^{2}$
}

Resumo: O voleibol é um dos esportes mais praticados no Brasil, sobretudo por crianças e adolescentes em idade escolar. Sabe-se que os hábitos adquiridos nessas idades refletem no comportamento quando adultos. Desta forma, o presente estudo tem por objetivo investigar as implicações da prática do voleibol escolar nos hábitos esportivos de adultos. Para isso, foram entrevistados adultos que tiveram contato com o voleibol na escola em suas diferentes manifestações esportivas. Após a coleta de dados, foi elaborada uma classificação dos resultados, categorização e análise de conteúdos. Foram encontradas diferentes respostas nos grupos estudados, ainda assim, alguns padrões foram percebidos, como no grupo dos adultos que hoje não praticam voleibol, em que a maioria afirmou ter presenciado a falta de estímulos na escola. Já no grupo que hoje pratica voleibol de rendimento, grande parte dos relatos dão conta de que a escola teve total influência no tipo de prática realizada atualmente, mas vinculando às experiências que tiveram em horários extraclasse. Quanto aos que praticam voleibol por lazer, foi o grupo que apresentou as mais variadas respostas, mencionando motivos como incentivo de amigos, falta de outra opção de lazer ou opção para manutenção da saúde.

Palavras-chave: Voleibol. Saúde. Escola.

\section{INTRODUÇÃO}

O esporte na escola, segundo Dias (2007), tem como objetivo principal fazer com que todas as crianças estejam incluídas na prática, vivenciando as atividades e tendo aprimoramentos físicos e outros vários benefícios decorrentes do mesmo. Além disso, promove o convívio geral, a sociabilidade, a criação de hábitos que levam os indivíduos a interagir uns com os outros e também contribui para que se tornem, no futuro, pessoas capazes de exercer a cidadania. $\mathrm{O}$ esporte dentro da escola faz com que a criança sinta-se motivada

1 Graduado, Educação Física - Licenciatura, UNIVATES, gkoerbes@universo.univates.br

2 Doutor em Ciências: Ambiente e Desenvolvimento, Docente do curso de Educação Física, UNIVATES, rodrigorother@univates.br 
a desenvolver o seu repertório motor e superar dificuldades; faz com que os aluno sejam mais saudáveis, sem a tendência de desenvolver algum problema de saúde durante sua vida adulta (MOSCARDE; ALVES; GREGOL, 2013).

Durante o desenvolvimento da prática pedagógica, Moscarde, Alves e Gregol (2013) explicam que o professor não deve fazer com que seja incitada a prática somente pela competição, mas sim pela vivência, a fim de desenvolver hábitos saudáveis e de companheirismo entre os alunos. As práticas com este tipo de conotação são denominadas por Tubino (1993) como esporte participação. A exemplo disso temos os esportes como conteúdo das aulas de Educação Física, que buscam incluir todos os alunos, criar o gosto e o prazer por praticar atividades físicas e proporcionar benefícios para a saúde do aluno.

Já em contrapartida a isso, também há alunos que se interessam pela competição, por formar equipes para disputas de jogos escolares, entre outros. Ainda segundo Tubino (1993), o esporte praticado com o objetivo de melhorar a performance é chamado esporte de rendimento. Este, em muitos casos, também é oferecido na escola, porém, fora das aulas de Educação Física, normalmente em horários do turno inverso, de forma complementar.

Já o esporte lazer, praticado fora do âmbito escolar, faz com que seja favorecida a convivência e a busca de melhor qualidade de vida por seus praticantes, fazendo com que o grupo de convivência de amigos seja ampliado. Dessa forma, promove-se o intercâmbio de informações e aumenta-se o convívio entre as pessoas, segundo a Secretaria do Turismo Esporte e Lazer (STEL/RS).

Durante a prática dessas atividades na escola, percebe-se que alguns alunos passam a gostar mais de determinadas atividades do que de outras. Sendo assim, suas escolhas podem ser direcionadas enquanto estes encontramse em idade escolar, e a prática passa a acompanhá-los durante a sua vida adulta.

Um dos esportes utilizados pela escola tanto na manifestação participativa como na competitiva, pelas características que apresenta é o voleibol, que também se configura como uma das modalidades mais praticadas no país. O voleibol promove o desenvolvimento do trabalho em grupo e o companheirismo, sendo que para vencer é necessária habilidade individual aliada a ações coletivas organizadas. Segundo Barroso e Darido (2009), esta modalidade faz com que os alunos trabalhem em equipe, desenvolvendo habilidades, atuando em conjunto e também fazendo com que o praticante adquira equilíbrio emocional.

Com base nesse pressuposto, este estudo objetivou relacionar a manifestação esportiva do voleibol praticado na escola com as implicações nos hábitos esportivos adotados na idade adulta. 


\section{MATERIAIS E MÉTODOS}

Este estudo teve caráter qualitativo e descritivo, o que possibilitou interpretar e descrever os significados e sentidos dados pelos participantes aos fenômenos objeto de investigação.

Foram convidados a participar do estudo 30 adultos de ambos os sexos, com idades entre 18 e 30 anos, praticantes e não praticantes de diferentes manifestações esportivas da modalidade voleibol, provenientes de municípios do Vale do Taquari/RS. A estes, foi aplicada um entrevista semiestruturada questionando-os sobre como foi seu contato com o voleibol quando esteve na escola e se isso ocasionou alguma implicação na prática esportiva realizada na idade adulta. Os entrevistados foram separados em três grupos: os que atualmente praticam voleibol de rendimento, praticantes de voleibol de lazer e não praticantes, sendo cada grupo composto por dez pessoas.

Os entrevistados foram escolhidos de forma intencional, sendo que os praticantes na modalidade de rendimento foram buscados em clubes onde praticam tal modalidade; os praticantes da modalidade de lazer foram procurados em espaços esportivos que alugam horários para esse fim; e as demais pessoas não praticantes foram escolhidas aleatoriamente.

As respostas obtidas nas entrevistas foram categorizadas de acordo com as manifestações esportivas praticadas atualmente e submetidas à análise, triangulando as informações com o referencial teórico existente e com as interpretações do pesquisador.

\section{RESULTADOS}

\section{a) Significado das práticas realizadas na escola:}

Os adultos que praticam atualmente voleibol na forma de lazer expõem que existia voleibol nas suas aulas de Educação Física quando jovens, mas em alguns casos os professores ou até mesmo os próprios entrevistados não participavam dos jogos, definindo a prática como monótona e sem continuidade. Os entrevistados que relataram haver tido boas aulas de Educação Física afirmaram que não praticavam por não gostarem da modalidade ou pelo pouco incentivo por parte do professor.

Já os adultos que seguem praticando voleibol na forma de rendimento, participando de competições, relataram que as vivências que tiveram no voleibol escolar foram muito importantes para a construção dos seus hábitos atuais. Citaram que a técnica aprendida, as estratégias de jogo e a convivência em grupo foram fundamentais naquela época. Alguns entrevistados deste grupo relataram que durante sua prática escolar não tiveram o hábito de praticar esta modalidade esportiva, mas com o decorrer do tempo passaram a gostar mais, pois seus amigos a praticavam também. Outros também relataram 
a importância da prática no turno inverso, já que os ajudou a conhecer mais os regulamentos, técnicas e aprimorar os seus gestos técnicos, facilitando o seu emprego na hora do jogo.

O grupo de pessoas não praticantes de voleibol atualmente relatou que as práticas na escola, na maioria dos casos, não trazia estímulo suficiente para que se pudesse tomar gosto por este esporte, ou seja, faltava estímulo por parte dos professores que ministravam as aulas e também por parte dos alunos, que não se motivavam a praticar o voleibol por falta de interesse com a disciplina. Hoje, a maioria destes entrevistados continua sem a prática do voleibol e relata que isso não interfere em suas vidas.

\section{b) Motivações para praticar voleibol na idade adulta}

A grande maioria dos entrevistados que praticam o voleibol por lazer relatou que busca, com isso, uma boa qualidade de vida e prevenção de doenças, juntamente com o bem estar que o esporte promove, por ser um trabalho em grupo que estimula o convívio com os amigos/colegas de prática. A grande maioria dos entrevistados afirma ir de carro até o local onde ocorre o jogo, com os demais companheiros, estreitando, assim, seus laços de amizade e companheirismo. Esses entrevistados reforçam que, de alguma forma, na idade adulta, voltaram a praticar o voleibol, mas não com o objetivo que tinham na escola, que era de aprender um jogo, e sim com o objetivo de promover o bem estar, a manutenção da forma física, a relação com os demais praticantes e o convívio em grupo.

Sobre as práticas atuais, os entrevistados do grupo de rendimento também relataram ser o bem estar, o trabalho em grupo e o companheirismo existente no ambiente esportivo o que os motiva para este tipo de prática atualmente. Alguns responderam, ainda, que esta prática faz bem para o seu desenvolvimento intelectual e emocional, e os mantêm ocupados com alguma coisa no decorrer dos dias. Conhecer novas pessoas e lugares e estarem dispostos a novos desafios também foram citados como motivadores para seguirem praticando.

Quanto ao grupo de não praticantes, os relatos dão conta de que não praticam voleibol por falta de interesse e também por não terem recebido o estimulo necessário na escola, seja por parte do professor ou mesmo dos alunos, o que aponta como um fator determinante para a descontinuidade desta prática esportiva em suas vidas.

\section{c) Possíveis relações entre as práticas realizadas na escola e na idade adulta:}

O grupo de não praticantes relata que estas relações existem, pois na idade escolar não praticavam por falta de estímulos (tanto de professores quanto de alunos) e seguem não praticando, ou seja, esta relação pode ser verificada, mas de forma negativa. 
Os entrevistados que praticam voleibol na forma de rendimento afirmam que há relação, já que foi na escola foi que a maioria aprendeu a jogar, com o incentivo constante do professor e de colegas. Foi o lugar onde eles realmente aprenderam o significado do jogo com suas regras, movimentos, técnicas e execução de movimentos. Os entrevistados relataram também que tiveram o auxílio de turnos extraclasse para que pudessem aprimorar os movimentos aprendidos em aula e, assim, conseguissem executá-los de forma mais precisa e correta, além de possibilitá-los a disputar jogos escolares.

Quanto a esta relação para o grupo de praticantes de lazer, parte dos entrevistados relatou que foi muito bom praticar voleibol na escola, e escolheram a prática para dar seguimento na sua vida adulta. Os motivos citados foram que o antigo professor incentivava a prática e a buscar sempre mais, levando-os a se identificarem com o voleibol. Mas da mesma forma, uma porção dos entrevistados relatou que a escola não teve nenhuma relação, que simplesmente escolheram esta prática por se tratar de uma possibilidade de convívio em grupo com seus amigos, sem que a escola fosse um fator determinante para sua escolha.

Um ponto que deve ser abordado mediante as respostas dos entrevistados é a relação de interesse do professor para as práticas, se este profissional está mesmo empenhado em desenvolver seu papel de docente ou está ali apenas ocupando um espaço e fazendo com que os praticantes acabem não tendo uma boa prática com conteúdos e métodos coerentes. Mediante os resultados apresentados, podemos fazer mais uma relação, que é o interesse do professor em desempenhar seu papel durante as aulas.

\section{DISCUSSÃO}

Os entrevistados do grupo de lazer foram os que forneceram respostas mais diversificadas. Entretanto, é possível visualizar um padrão entre elas, que seria o de haver ou não estímulos, bem como a existência de estímulos negativos, fazendo com que alguns alunos praticassem e outros não, gerando uma grande divergência dentro deste grupo estudado.

Já os entrevistados do grupo de rendimento falaram que a presença de um bom professor que os incentivasse a praticar e também a existência de um horário extraclasse fez com que estes optassem pela continuidade da prática na idade adulta, que também oferece benefícios como o convívio em grupo, o companheirismo e a manutenção da saúde. Neste grupo, a presença do professor foi, em grande parte, determinante para que houvesse a continuidade da prática do voleibol.

No grupo de não praticantes, o professor não proporcionava os estímulos corretos e também não realizava práticas que fizessem com que os alunos criassem o hábito de jogar voleibol, assim, esses optaram por não praticá-lo. Além disso, houve a presença de estímulos negativos, como a total 
ausência do professor nas aulas e sua constante critica aos alunos, fazendo com que eles desgostassem de praticar a modalidade voleibol.

De acordo com Dias (2007), o esporte na escola é fundamental para desenvolver o aluno tanto em seus aspectos cognitivos quanto comportamentais. Alguns estudantes, durante a idade escolar, têm experiências boas e ruins que levam para a sua vida adulta, e assim, acabam fazendo ou não uso dessas experiências.

Moscarde, Alves e Gregol (2013) apontam que o esporte na escola desenvolve um aluno saudável, e aqueles que o praticam têm menos chances de desenvolver doenças, contribuindo, dessa forma, para uma boa qualidade de vida. Este é um ponto importante que os alunos devem ter em mente quando estão praticando uma atividade física na escola. Nesse sentido, é preciso que haja práticas pedagógicas variadas para que os estudantes ampliem o seu repertório motor.

Diante das muitas respostas encontradas nos grupos estudados, verifica-se que os significados à prática realizada quem dá é o aluno, segundo as vivências que presenciou, juntamente com todos os anos de práticas desenvolvidas dentro da escola, mas também com grande influência do professor, sendo esse o maior incentivador desta prática.

Na escola, o professor tem um papel fundamental, que é promover uma prática pedagógica coerente e que supra as necessidades do aluno quanto a conteúdo e aprendizado, solucionando os conflitos existentes. Um das funções do professor é incentivar o aluno a compreender os sentidos que os jogos podem oferecer a ele e que esses mesmos jogos podem ter. A resolução de divergências ou de discussões que esta prática pode apresentar e também as mudanças que podem vir das normas do jogo são alguns exemplos, aponta Betti (1993).

Cruz e Silva (2002) citam que o professor é muito importante na sociedade e para o aluno. Por esse motivo, deve ter ciência de que suas atitudes dentro do âmbito escolar oscipalm de fáceis a difíceis, do menor ao maior grau, havendo uma instrumentalização para estimular que quando seus alunos cheguem à vida adulta, como cidadãos, possa usar os conhecimentos adquiridos de forma correta e coerente.

Menegolla e Sant'anna (2001, p. 11, apud CASTRO; TUCUNDUVA; ARNS, 2008, p. 7), afirmam que "a educação, a escola e o ensino são os grandes meios que o homem busca para poder realizar o seu projeto de vida. Portanto, cabe à escola e aos professores o dever de planejar a sua ação educativa para construir o seu bem viver". A partir dessa citação, ressalta-se o valor da escola, o que é reiterado por Castro, Tucunduva e Arns (2008), que abordam a grande importância que tanto a escola quanto o professor têm na formação dos cidadãos. Assim, o indivíduo deve estar ciente de seus direitos e obrigações. No entanto, apesar de todo este planejamento ser de uma importância muito grande, há professores que negligenciam sua prática pedagógica fazendo 
uso do improviso durante as aulas. Assim, dificilmente conseguirão atingir o objetivo de formar cidadãos.

\section{CONSIDERAÇÕES FINAIS}

Emerge a importância de um bom professor de Educação Física para criação de hábitos saudáveis seguidos na idade adulta. Este deve oferecer incentivo constante para que os alunos sintam-se motivados a seguir com a prática de esportes dentro do âmbito escolar, seja nas aulas ou em oferta de atividades extra classe.

Pode-se concluir também que durante as pesquisas realizadas com os grupos mencionados evidenciou-se a grande falta de participação do professor nas aulas. Esta situação foi mais presente no grupo de participação, onde houve a maior variedade de respostas encontradas.

Com todas as respostas encontradas durante a pesquisa realizada podese também concluir que o esporte na escola é fundamental para que os alunos possam ter uma experimentação corporal, ampliar o seu repertório motor e crescer como indivíduos, para, com isso, integrar a sociedade.

\section{REFERÊNCIAS}

BARROSO, André Luís Rugiero; DARIDO, Suraya Cristina. Voleibol escolar: uma proposta de ensino nas dimensões conceitual, procedimental e atitudinal do conteúdo. Rev. bras. Educ. Fís. Esporte, São Paulo, v.24, n.2, p.179-94, abr./jun. 2010.

BETTI, Irene Conceição Rangel. Esporte na Escola: mas é só isso, professor? Motriz, v. 1, n. 1, p. $25-31$, jun. 1999.

BONI, Valdete; QUARESMA, Ś́lvia Jurema. Aprendendo a entrevistar: como fazer entrevistas em Ciências Sociais. Revista Eletrônica dos Pós Graduandos em Sociologia Política da UFSC, [S.l.], v. 2, n. 1(3), p. 68-80, jan./jul. 2005.

CASTRO, Patricia Aparecida Pereira Penkal de; TUCUNDUVA, Cristiane Costa; ARNS, Elaine Mandelli. A IMPORTÂNCIA DO PLANEJAMENTO DAS AULAS PARA ORGANIZAÇAO DO TRABALHO DO PROFESSOR EM SUA PRÁTICA DOCENTE. Revista Científica de Educação, v. 10, n. 10, jan./jun. 2008.

CRUZ. Ana Maria Lima; SILVA. Paulo da Trindade Nerys: A prática pedagógica dos professores de educação física nas escolas públicas de São Luís (MA). (2002) p.12.

DIAS, Renata. A importância do esporte na educação. 2007. <http:/ /www. planetaeducacao.com.br/portal/artigo.asp?artigo=790>. Acesso em: 07 mai. 2016.

GERHARDT, Tatiana Engel; SILVEIRA, Denise Tolfo. Métodos de pesquisa. Coordenado pela Universidade Aberta do Brasil - UAB/UFRGS e pelo Curso de 
Graduação Tecnológica - Planejamento e Gestão para o Desenvolvimento Rural da SEAD/UFRGS. Porto Alegre: Editora da UFRGS, 2009.

MINAYO; M.C.S. O desafio do Conhecimento: Pesquisa qualitativa em saúde. $10^{\circ}$ edição. São Paulo. 2007.

MOSCARDE, Everton Roberto; ALVES Emerson; GREGOL, Dhioni Cleiton. Os benefícios do voleibol no âmbito escolar. EFDeportes.com - Revista Digital, Buenos Aires, ano 18, n. 181, junio, 2013. Disponível em: <http:/ / www.efdeportes.com/ efd181/os-beneficios-do-voleibol-no-ambito-escolar.htm>. Acesso em: 07 mai. 2016.

NEVES, José Luis. Pesquisa qualitativa - Características, usos e possibilidades. Caderno de Pesquisa em Administração, São Paulo, v.1, n. 3, 2. sem. 1996.

RODRIGUES, William Costa. Metodologia Científica. Paracambi: FAETEC/IST, 2007.

ROTHER, Rodrigo Lara. Análise da formação de atletas no voleibol brasileiro sob a perspectiva da teoria bioecológica do desenvolvimento humano. Centro Universitário Univates Programa de Pós-Graduação Stricto Sensu Mestrado em Ambiente e Desenvolvimento. Lajeado, out. 2014.

STEL RS; Secretaria do Turismo Esporte e Lazer do Rio Grande do Sul. http:/ /www. setel.rs.gov.br/conteudo/2167/Setel-RS Acesso dia 15/11/2016

TRIVINOS, Augusto Nivaldo Silva. Introdução à pesquisa em ciências sociais : a pesquisa qualitativa em educação. Editora Atlas. São Paulo. 1995.

TUBINO, Manoel; O que é esporte. Editora Brasiliense. São Paulo, 1993. 